\title{
The Impact of COVID-19 on College Students' Consumption Behaviors
}

\author{
Xiaoran $\mathrm{Chu}^{1}$ \\ ${ }^{1}$ Division of Education, Siena Heights University, Adrian, USA \\ Correspondence: Xiaoran Chu, Division of Education, Siena Heights University, Adrian, Michigan, USA.
}

Received: June 6, 2021

Accepted: July 8, 2021

Online Published: July 31, 2021

doi:10.5430/irhe.v6n2p32

URL: https://doi.org/10.5430/irhe.v6n2p32

\begin{abstract}
The COVID-19 pandemic has hit global economy, and it has also greatly affected all industries with college students as the core consumer group. Through the questionnaire survey, this paper found that during the epidemic period, college students' consumption in catering and tourism decreased significantly, the utilization rate of supermarket flash delivery services was not high, and they were not satisfied with the services provided by online education. In terms of college students' consumption tendency after the epidemic, their willingness to consume in catering industry is relatively strong, while their willingness to consume in tourism is not high. The overall consumption level of college students has been on the rise during the epidemic period, with specific increases in online spending on education, daily necessities, online shopping and medical supplies, and decreases in catering, offline retail and traffic tour. Based on the problems found and the development rules of the industries, this paper puts forward corresponding operational countermeasures for the operators of the above industries to help them better carry out the post-epidemic recovery work.
\end{abstract}

Keywords: COVID-19 pandemic, college students, consumption behavior

\section{Introduction}

The COVID-19 outbreak in late December 2019 has had a negative impact on the world's economy by delaying work and school starts across the world. College students are the main force in the catering takeout, online shopping and other consumer areas, and the change of college students' consumer behaviors has a profound impact on these industries. In addition, changes in college students' consumption behaviors caused by the epidemic will also affect the decisions of those practitioners in online education and supermarket flash delivery, which have sprung up during the epidemic.

Through questionnaire survey, this paper studies the changes of college students' consumption level in catering, tourism and other industries after the outbreak of the epidemic, their attitudes towards online education and supermarket flash delivery services during the outbreak, and people's consumption tendency in the above industries after the outbreak of the epidemic. By investigating the changes of consumer behavior of college students caused by the epidemic and analyzing the possible causes of such changes, valuable reference materials and reasonable suggestions can be provided to the operators of relevant industries. And it is also of great significance to study the consumer psychology and behavior of college students.

\section{Literature Review}

Scholars have studied the influences of "SARS" epidemic on consumer behaviors during the outbreak of SARS epidemic. For example, in the article "The atypical impact of the epidemic on consumer behavior", Wang Min analyzed the psychological and behavioral changes of consumers caused by "SARS" epidemic and put forward countermeasures taken by enterprises to respond to the psychological and behavioral changes of consumers (Min Wang, p. 90). After the outbreak of COVID-19, some scholars also analyzed the changes in consumer behaviors. For example, Wang Jianming predicted the characteristics of consumer products or services in the future in "Influence of the COVID-19 epidemic on consumption behavior pattern and countermeasures", and proposed countermeasures for the government and relevant enterprises (Jianming Wang, No. 7) However, previous literature studies mainly focus on simple qualitative analysis, without specific analysis of consumer psychology and behavior changes in different fields. For the main aspects of college students' consumption, we refer to Zheng Junlei's "Consumption characteristics and educational guidance of contemporary college students -- Based on a case study of Nanjing Audit University" and believe that college students' consumption mainly focuses on catering, personal communication, 
education and training, leisure and entertainment (Junlei Zheng, pp. 84-88). To sum up, this paper conducted a questionnaire survey on the psychological and behavioral changes of college students in different consumption fields. Then, the paper quantified the impact of the epidemic on consumer behavior in different industries, and mainly studied the following questions for catering and tourism: 1) Changes in the number of college students dining together during the past Spring Festival and this Spring Festival? 2) What are college students' expectations for catering and tourism after the outbreak? 3) What are college students' plans for dining and traveling after the outbreak? It is divided into two parts for discussion because of its much analysis content. For online education and supermarket flash delivery, the paper mainly focuses on: 4) The use of online education and supermarket flash delivery services and satisfaction degree? As they have similar problems and are both widely promoted services during the epidemic, they are discussed and compared in one section.

\section{Research Methodology}

The main research method adopted by the author in this paper is questionnaire survey, which is to ask questions in the form of online questionnaire, send them to relevant people who fill in the answers, and collect them for sorting, statistics and research (Yuna Cui, \& Beibei Zhou, pp. 829-833). For this survey, a total of 100 questionnaires were issued, 99 of which could be retrieved with a recovery rate of $99 \%$. The respondents' gender, grade, city, consumption situation in catering and tourism before and after the outbreak of the epidemic, and their expectation level of consumption behaviors such as dining and traveling after the outbreak. The author has a preliminary understanding of online education and supermarket flash delivery services.

\section{Data Analysis}

\subsection{Catering Industry}

The questionnaires showed that before the epidemic, more than 70 percent of college students had dinner together more than once, while after the epidemic, 70 percent of college students had no dinner together or only once. More than half (55 percent) of college students have had more than four family dinners during the Spring Festival in the past, but this year the number is rapidly decreasing (only 6 percent having more than four times). The results of the variance analysis show that there is a significant difference in the frequency of college students' dinner party this year compared with previous years. It can be seen that college students have made efforts to help control the epidemic through their own practical actions. Of course, self-isolation also has a significant impact on the catering industry. From the recovery of the catering industry, approximately 53\% of college students are looking forward to dinner together, and approximately $30 \%$ are willing to dinner together after a week. It can be seen that college students have high expectations for dinner parties, and the turnover of surrounding restaurants in colleges and universities may be greatly improved within one week of the new semester, recovering from the impact of the epidemic during the Spring Festival, and related industries driven by catering will be improved in operation. At the same time, according to the data, $51 \%$ of the respondents think that there is no dinner party at present, until there is an arrangement. Therefore, it is suggested that businesses should seize the opportunity to stimulate consumption through promotional activities such as discounts, which is expected to produce good results.

Table 1. Variance analysis result

\begin{tabular}{|c|c|c|c|c|c|c|}
\hline & \multicolumn{4}{|c|}{$\begin{array}{l}\text { How many times did you and your family have dinner } \\
\text { together during Spring Festival in previous years? (Mean } \pm \\
\text { standard deviation) }\end{array}$} & \multirow[t]{2}{*}{$\mathrm{F}$} & \multirow[t]{2}{*}{$\mathrm{P}$} \\
\hline & $0-1(n=13)$ & $2-3(n=8)$ & $4-5(n=8)$ & $\begin{array}{l}\text { More than } 6 \\
\text { times or more } \\
(\mathrm{n}=21)\end{array}$ & & \\
\hline $\begin{array}{l}\text { How many times have you and } \\
\text { your family had dinner } \\
\text { together during this Spring } \\
\text { Festival }\end{array}$ & $1.08 \pm 0.28$ & $1.00 \pm 0.00$ & $1.13 \pm 0.35$ & $1.95 \pm 1.16$ & 5.104 & $0.004 * *$ \\
\hline \multicolumn{7}{|c|}{$* \mathrm{p}<0.05 * *<0.01$} \\
\hline
\end{tabular}


Table 2. Your expectation towards dining together after the resumption of catering

\begin{tabular}{lll}
\hline Options & Total & Proportion \\
\hline Extremely strong & 21 & $21.21 \%$ \\
\hline A little strong & 32 & $32.32 \%$ \\
\hline Don't care & 46 & $46.46 \%$ \\
\hline $\begin{array}{l}\text { The number of respondents who effectively } \\
\text { filled in the form }\end{array}$ & 99 & \\
\hline
\end{tabular}

Table 3. The time you expect for the next dinner party to be arranged when the catering industry resumes

\begin{tabular}{lll}
\hline Options & Total & Proportion \\
\hline Immediately & 17 & $17.17 \%$ \\
\hline One week later & 15 & $15.15 \%$ \\
\hline Half a month later & 7 & $7.07 \%$ \\
\hline No worry and wait for one month & 10 & $10.1 \%$ \\
\hline $\begin{array}{l}\text { No arrangement at present and take } \\
\text { consideration when it comes }\end{array}$ & 50 & $50.51 \%$ \\
\hline $\begin{array}{l}\text { The number of respondents who effectively } \\
\text { filled in the form }\end{array}$ & 99 & \\
\hline
\end{tabular}

In short, from the catering industry, questionnaire data and variance analysis show that there is a significant difference between the frequency of college students' dinner parties this year and previous years. College students consume very little during the epidemic period, which has a great impact on the catering industry, especially businesses targeted at college students, while curbing the epidemic. At the same time, most college students have a strong desire to consume after the epidemic, and sales are expected to rebound in half a month. Comparative analysis shows that more than $10 \%$ of college students have potential consumption possibilities except those who have no idea of dining together at all. In view of the consumption level and consumption psychology of college students after the epidemic, it is suggested to attract college students' consumption and bring back potential customers by strengthening stores' attention to hygiene environment, offering discounts and promoting sales, or vigorously promoting through multiple channels such as wechat moments promotion and QQ space forwarding.

\subsection{Tourism Industry}

As you can see from Figure 1 and Figure 2, there are more than fifty percent of the students did not plan to travel in the forthcoming year. Only twenty percent of the students said they would increase the frequency of travel in the next year. It can be found that the willingness of college students to travel is not high. Merely eight percent of college students are expected to take a trip within one month after the tourism industry returns to a normal state. There may be two reasons which include influences brought about by beginning of school and limited economic capacity of college students who have not yet achieved economic independence. But according to the questionnaire, while $67 \%$ of participants thought the frequency of travel would not change in the coming year, $17 \%$ of participants thought the frequency of their travel would slightly increase, higher than the total sum of those who thought they would travel a little less $(6 \%)$ and a lot less $(7 \%)$. It is showed through the questionnaire statistics that the outbreak of the epidemic is not as expected to stimulate the increase of the college students for the coming year's tourism consumption. Hence, it can be conjectured that the negative impact of the epidemic on tourism in the coming period of time is probably more serious than on the catering industry in the long run. The reason may be because the expenditure required on travel far outweighs the spending of daily dining together. Although the epidemic has depressed the mood of college students to travel, this pent-up mood may be eliminated due to the impact of the epidemic on the economic income of each family. Therefore, it is suggested that the tourism industry should reduce the ticket cost or expand the publicity to revive the domestic tourism economy. 


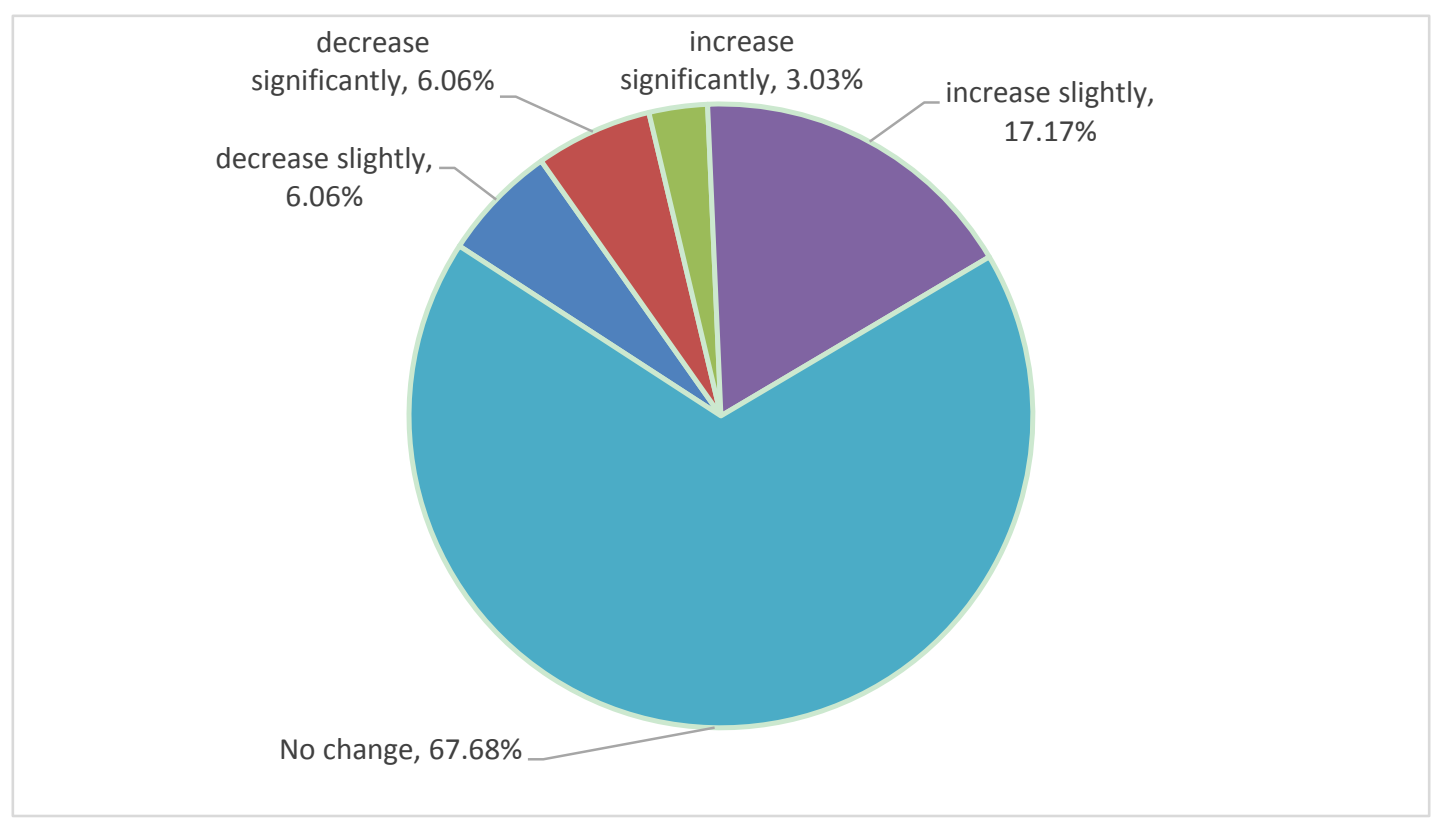

Figure 1 . The frequency of travel in the next year predicted by college students

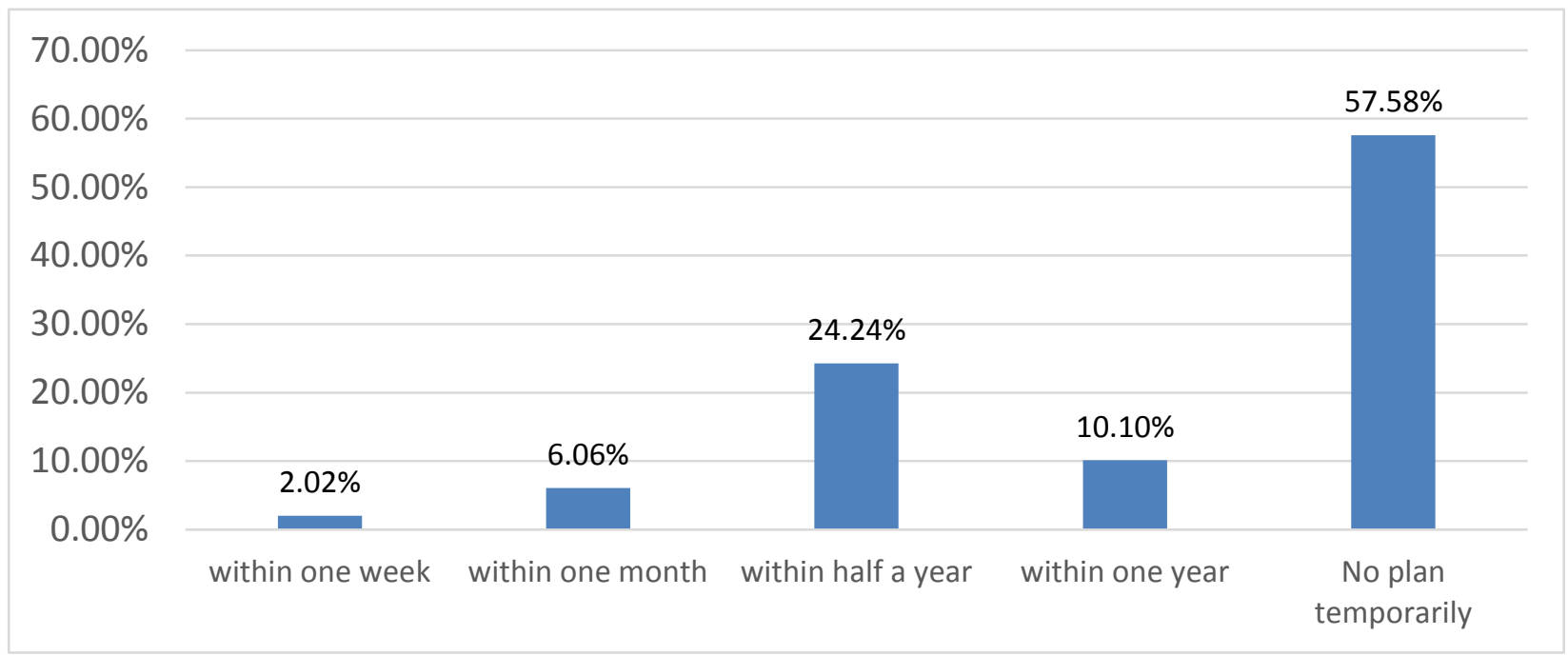

Figure 2. The time of travel the next time predicted by college students

In conclusion, it can be seen from the tourism industry that college students temporarily have no strong will to travel within a year and they almost have no will to travel as stimulated by limit of the epidemic. Even some users said they would reduce the travel plan thereafter for the following three reasons: (1) Influences incurred by delay in the time of school opening, (2) limited economic condition of college students and (3) worry about the sanitary environment of tourist attractions. At the same time, in terms of the frequency of college students' trips in the next year, a slight increase $(17.17 \%)$ is more than the sum of a slight decrease $(6.06 \%)$ and a significant decrease $(6.06 \%)$. Therefore, relevant industries can pay attention to guiding and cultivating their potential users.

\subsection{Online Education and Supermarket Flash Delivery}

Only thirty percent of college students said they would use the method of online education in their learning thereafter, 
whereas nearly half of the students said they were only willing to use online education methods during the outbreak of the epidemic. A total of 70 percent of college students showed they would support the method of online education during the epidemic. This shows that the online education initiative during the epidemic has won the understanding and support of most college students. At the same time, most students think that the effect of online education is not as good as offline classroom learning, which reflects that the online education technology currently used by schools has not met the learning needs of most college students. This has hindered the marketization of online education to some extent. Online education technology still has great room for progress in the future, but problems such as the lack of self-control, the lack of paper materials and the stability of network links need to be solved.

Table 4. College students' attitude towards online education which replaces offline classroom teaching after the breakout of the epidemic

\begin{tabular}{lll}
\hline Options & Total & Proportion \\
\hline $\begin{array}{l}\text { Support, holding the view that it is an opportunity for } \\
\text { online education which will be used in the future }\end{array}$ & 33 & $33.33 \%$ \\
\hline $\begin{array}{l}\text { Support, holding the view that online education will } \\
\text { only be used during the epidemic }\end{array}$ & 48 & $48.48 \%$ \\
\hline $\begin{array}{l}\text { Don't support, but hold an optimistic view towards } \\
\text { online education }\end{array}$ & 10 & $10.1 \%$ \\
\hline $\begin{array}{l}\text { Don't support and will not use online education in the } \\
\text { future }\end{array}$ & 5 & $5.05 \%$ \\
\hline Others & 3 & $3.03 \%$ \\
\hline $\begin{array}{l}\text { The number of people who have effectively filled in the } \\
\text { form }\end{array}$ & 99 & \\
\hline
\end{tabular}

Sixty percent of college students have never used services such as supermarket flash delivery or home delivery during the pandemic. It has become extremely difficult for college students to go shopping when most communities across the whole country are locked down due to the epidemic. However, most college students still do not use similar services in supermarkets, indicating that there may be problems such as inadequate publicity, unreasonable price setting, inhumane service mode, and not yet widespread supermarket flash delivery in many areas.

Table 5. The times of usage of supermarket flash delivery and take-out by college students during the epidemic

\begin{tabular}{lll}
\hline Option & Total & Proportion \\
\hline Zero & 63 & $63.64 \%$ \\
\hline $1-3$ & 27 & $27.27 \%$ \\
\hline $4-8$ & 5 & $5.05 \%$ \\
\hline More than 8 & 4 & $4.04 \%$ \\
\hline The number of people who have effectively filled in the form & 99 & \\
\hline
\end{tabular}

From the perspective of online education and supermarket flash delivery, consumption has increased in both industries under the impact of the epidemic. For more than half of the users, neither online education nor supermarket flash delivery has achieved the effects expected by consumers. Problems such as stuttering in online education still need to be overcome. As for the supermarket flash delivery, the residence of many second and third-tier college students in the survey has not been promoted, which shows that there is still a lot of room for improvement in service level and hardware technology. The pandemic has boosted public understanding and influence of the two industries. It is suggested that practitioners should improve the system and services according to the suggestions made by users in this epidemic. Meanwhile, they still need to do a good job in public relations to improve the image of enterprises and even the industry. 


\subsection{Summary of Influences Upon Consumption}

In the questionnaire, the consumption level of college students in all aspects before the epidemic is set as a cardinal number 3. The survey shows that the epidemic has led to an increase to 3.35 in the overall consumption level of college students, mainly in the areas of wired entertainment (3.37), daily necessities (3.34), online shopping (3.34), and medical supplies (3.42). Areas which have decreased include catering (2.8), offline retail (2.68), and transportation and tourism (2.28). It can be seen from the data that the epidemic has improved college students' awareness of health protection and has a positive impact on the development of the medical industry. After the outbreak of the epidemic, the consumption level of medical supplies, online entertainment, daily necessities and online shopping is relatively high. The reasons for the increase in consumption level in these aspects may be as follows: (1) During the epidemic period, the publicity of public health safety has been put in place, the awareness of protection among college students has been improved, and the purchase of medical supplies has increased; (2) The overall price level rises and college students can only take activities at home, so consumption is relatively simple; (3) During the epidemic, college students are in a bad mood and under increased pressure. Spending on online shopping and entertainment has rose, while offline retail and transportation and travel remained low, which is in line with expectations.

\section{Concluding Remarks}

The epidemic has, to some extent, suppressed the consumption demand of college students, but their consumption enthusiasm did not increase sharply after the epidemic ended. Some industries that saw a short term boom during the epidemic, such as online education and supermarket flash delivery, are not recognized by most college students for their services. How to make the short term prosperity of these enterprises in the epidemic to obtain long-term development is worth to think over for operators. From the catering industry, the consumption of college students is very low during the epidemic period, and most of them have a strong desire to consume after the epidemic. It is expected that the sales will rebound in half a month. It is suggested that the stores should pay more attention to the sanitary environment, offer discounts and promote sales, or attract college students' consumption and bring back potential customers through wechat moments promotion and QQ space forwarding. From the perspective of the tourism industry, college students do not have a strong desire to travel in the coming year and will not travel due to the impact of the epidemic. Some users will even reduce their travel plans in the future. It is suggested that relevant industries attach importance to the guidance and cultivation of potential users after the epidemic. From the perspective of online education and supermarket flash delivery, consumers are not satisfied with their services, and their service level and hardware technology still have a lot of room for improvement. It is suggested that practitioners should improve the system and services according to the suggestions made by users of the epidemic, and do a good job in public relations to improve the image of enterprises and even the whole industry. In terms of consumption levels after the outbreak of the epidemic, spending on medical supplies, online entertainment, daily necessities and online shopping was relatively high during the epidemic period. Spending on online shopping and entertainment has rose, while offline retail and transportation and travel were lower, in line with expectations.

In the final survey of "Chinese college students' optimism about China's future economy", the majority of Chinese college students have confidence in the future development of China's economy. As the saying goes, "When young people are strong, China will be strong". Although the epidemic has largely affected their daily life and study, Chinese college students have not lost confidence in life and are optimistic about the future of China's economy. China's young people are marching into a post-epidemic future with vigor and vitality.

\section{References}

Cui, Y-N., \& Zhou, B-B. (2014). Analysis of college students' online game behavior in the era of new electronic products. Chinese Journal of Management Science, 22(S1), 829-833.

Gupta, S. B., \& Gupta, M. (2020). Technology and E-learning in higher education. Technology, 29(4), 1320-1325.

Sahu P. (2020). Closure of universities due to Coronavirus Disease 2019 (COVID-19): impact on education and mental health of students and academic staff. Cureus. https://doi.org/10.7759/cureus.7541

Shahzad, A., Chin, H. K., Altaf, M., \& Bajwa, F. A. (2020). Malaysian SMEs performance and the use of e-commerce: A multi-group analysis of click-and-mortar and pureplay E-retailers. Pakistan Journal of Commerce and Social Sciences (PJCSS), 14(1), 1-33.

Shereen, M. A., Khan, S., Kazmi, A., Bashir, N., \& Siddique, R. (2020). COVID-19 infection: Origin, transmission, and characteristics of human coronaviruses. J Adv Res., 24(7), 91-98. https://doi.org/10.1016/j.jare.2020.03.005 
Wang, J-M. (2020). Influence of the COVID-19 epidemic on consumption behavior pattern and countermeasures. China Business News, (7).

Wang, M. (2003). The atypical impact of the epidemic on consumer behavior. Economic Forum, (16), 90.

Zheng, J-L. (2019). Consumption characteristics and educational guidance of contemporary college students -- Based on a case study of Nanjing Audit University. Research on University Logistics, (1), 84-88.

\section{Copyrights}

Copyright for this article is retained by the author(s), with first publication rights granted to the journal.

This is an open-access article distributed under the terms and conditions of the Creative Commons Attribution license (http://creativecommons.org/licenses/by/4.0/). 